\title{
A história filosófica contra Rousseau
}

\author{
Philosophical history against Rousseau
}

\author{
Pedro Paulo Pimenta \\ pedronamba@gmail.com \\ (Universidade de São Paulo, São Paulo, Brasil)
}

\begin{abstract}
Resumo: Trata-se de mostrar como a história filosófica, gênero típico da época da Ilustração, foi utilizada como uma espécie de método alternativo à história conjectural, tal como concebida e utilizada por Rousseau no segundo Discurso. É o caso, notadamente, da History of America, do escocês William Roberston, onde o selvagem americano aparece como tipo do homem natural, inserido no quadro de uma teoria do desenvolvimento da sociedade através de estágios. A profundidade teórica e o potencial crítico da obra de Robertson foram identificados por Edmund Burke, seu primeiro e mais arguto leitor.
\end{abstract}

Palavras-Chave: história; conjectura; selvagem; eloquência.

\begin{abstract}
The aim of the article is to show how philosophical history, as conceived in the Enlightenment, was used as a kind of weapon against the conjectural method as delineated by Rousseau in the second Discourse. A prime example of such a strategy is William Robertson's History of America, in which the savage American is taken as a type for natural man that, as such, is part of a general theory of the development of society through stages. The theoretical and critical qualities of Robertson's work did not escape Edmund Burke, its first and prominent reader.
\end{abstract}

Keywords: history; conjecture; savage; eloquence.

DOI: http://dx.doi.org/10.11606/issn.2318-9800.v22i3p91-106

A História da América, do escocês William Robertson, publicada em 1777, é hoje um monumento esquecido. Em sua época, foi saudada como um clássico, posição que reteve até meados do século XIX. Robertson, que em 1777 detinha o posto de "historiador da coroa para a Escócia", era conhecido por uma História da Escócia (1756), concebida como um complemento à História da Inglaterra de seu amigo Hume, bem como por uma História de Carlos V (1762), verdadeira história da Europa moderna, livro engenhoso, que toma o monarca Habsburgo como ponto nodal de um processo que remonta à Idade Média, período a que Robertson retrocede para explicar as causas que levaram aos eventos que marcaram sua própria época - o século XVIII. Aos olhos de seus contemporâneos, Robertson ocupava o mesmo 
patamar que Voltaire e Hume, que o tinham como um par; para os aspirantes ao posto de historiador - considerado um título honorífico, desde que Cícero assim o tratara ${ }^{1}$-, Robertson era um modelo a ser imitado, e assim procedeu declaradamente Edward Gibbon. Não por outra razão, Sérgio Buarque de Holanda houve por bem se referir a esse quarteto - Voltaire, Hume, Robertson, Gibbon - como "os corifeus da historiografia ilustrada" (Buarque de Holanda, 1974).

Desde o momento em que foi publicada, a História da América encantou o público leitor. Não tanto pela reconstituição da conquista do continente americano pelos espanhóis - episódio que já na época era considerado como um capítulo censurável nos anais da história moderna -, como pelo volume IV, dedicado ao estudo da geografia, da ecologia e da antropologia do "Novo Mundo".

Via de regra, como sabia todo historiador versado nos clássicos, o mais seguro e recomendável nessa arte capciosa é adotar um estilo calculado para o entendimento, que cuida de evitar o fomento das paixões e o encanto da imaginação - medida necessária, diga-se de passagem, dada a natureza algo obscura do assunto (poucos membros do público leitor europeu conhecem a América por experiência própria). A conquista de um continente, por extenso que seja, não chega a ser um fato novo, para os europeus, conhecedores das narrativas das guerras, de conquista e dominação, entre gregos e persas, romanos e bárbaros. Mutatis mutandis, a colonização da América por meios violentos pode ser entendida como um evento da mesma classe que aqueles, analogia justificada pela suposta proximidade (mas não identidade) entre os selvagens de hoje e os bárbaros de outrora, entre os europeus da cristandade e os povos mediterrâneos de Antiguidade. É assim que esse evento será compreendido por Hume, por exemplo (Hume, 1983). Robertson percebeu, no entanto, que uma história da América que se limitasse a tanto deixaria de lado o que há de verdadeiramente peculiar nesse evento, tipicamente moderno. Pois enquanto as guerras antigas eram motivadas por razões de ordem política, a expansão europeia moderna é movida pelo comércio (como assinala, novamente, Hume) ${ }^{2}$; e, se o que distinguia, aos olhos de gregos e romanos, os bárbaros dos cidadãos, eram os costumes, para os modernos do século XVIII, a marca da distinção entre o homem civilizado e o homem selvagem é o desdém deste último pelo comércio e pelas atividades a ele ligadas - agricultura extensiva, pastoreio intensivo, manufatura, circulação de bens, cobrança de impostos para a manutenção de um poder público. É no quadro dessa diferença que desponta a complexa e desafiadora figura do homem americano, que, contrariamente aos bárbaros de outrora, descritos pelos historiadores antigos em termos muito gerais, e não raro fantasiosos, foi objeto de intensa curiosidade direta dos europeus, por causa das missões de conversão patrocinadas pela Igreja. Graças

1 Ver Cícero, De legibus, I, 2, 5-7; Cícero, 2008.

2 Ver o ensaio "Da liberdade civil” - Hume, 1985. 
ao caráter militante da religião cristã, a literatura moderna de cunho etnográfico é muito mais rica do que tudo o que os antigos jamais disseram a respeito de outras nações. Com base nessa literatura, Robertson delineia um quadro vivo e sugestivo desse objeto instigante, que desafia a compreensão e alarga a compreensão da natureza humana. Em suma, no livro IV a História da América se torna o que todo livro do gênero deve ser, no século XVIII: uma obra de filosofia. ${ }^{3}$ Ouçamos Robertson:

Para contemplar a história da mente humana e chegar ao conhecimento perfeito de sua natureza e de suas operações, devemos contemplar o homem em todas as variadas situações em que ele se encontra, e acompanhá-lo em seu progresso por diferentes estágios da sociedade, à medida que avança gradualmente, da infância da vida civil rumo à sua maturidade e declínio (Robertson, 1777, pp.281-2).

Quando Robertson fala em "história da mente humana”, evoca o Ensaio sobre o entendimento, de Locke, cujo objetivo era "explicar", por meio do "simples método histórico..., as vias pelas quais o nosso entendimento alcança as noções que temos das coisas, e encontrar a fundação da diferente convicção dos homens a respeito, delimitando assim a certeza do nosso conhecimento" (Locke, 1978). Essa história descritiva da mente será mais completa, no entender de Robertson, se puder se beneficiar de uma descrição complementar da formação da mente humana em seu habitat natural (a vida em sociedade), como se encontra junto aos povos e às nações mais primitivas de que se tem conhecimento, ou seja, as que habitam o continente americano.

Portanto, embora o grosso da História da América verse sobre a chegada e instalação dos espanhóis no continente, essa trama estaria incompleta, no que se refere ao seu sentido mais profundo, se não incluísse uma descrição do continente e de seus habitantes no momento da chegada de Colombo. Esse exercício é necessariamente conjectural, baseia-se em informações obtidas pelos viajantes em missão ao continente e registradas em relatos publicados na Europa. Para Robertson, que aborda essa literatura com olhar filosófico, isto é, com vistas à constituição de uma teoria sobre a natureza humana que é também uma teoria social, é fundamental traçar e reforçar o contraste entre a passiva indolência dos nativos e a ativa diligência dos conquistadores, que logo se apercebem de uma verdade que parece ter escapado à percepção dos habitantes originais do continente; a saber, que este é predisposto, por natureza, à prática da agricultura e do comércio: “os colonos europeus desbravaram e cultivaram alguns pontos localizados ao longo da costa; mas os habitantes originais nada fizeram para aprimorar um solo dotado de praticamente todas as vantagens possíveis de localização e clima” (Robertson, 1777, I, 4, pp.257259, itálicos meus).

É possível inferir o passado a partir de circunstâncias presentes: se o estado

3 Ver "Ensaio sobre o estudo da literatura”, Gibbon, 2014. 
atual do solo mostra que dele não há cultivo, é lícito supor que desde tempos imemoriais tenha sido essa a situação, pois do contrário haveria ou resquícios de avanço rumo a artes mecânicas ou o testemunho inequívoco da prática destas entre os selvagens. Não é o que se vê, porém, na imensa vastidão do continente; e pode-se afirmar, com toda segurança, como "questão de fato" (matter of fact), que

Na América, o homem aparece sob a forma mais rudimentar em que podemos conceber que ele subsistiria. Observamos comunidades que apenas começam a se reunir, e podemos examinar os sentimentos e ações de seres humanos na infância da vida social, quando imperfeitamente eles sentem a força de seus laços e mal abandonaram sua liberdade nativa. Esse estado de primeva simplicidade, que em nosso continente era conhecido apenas pela fantasiosa descrição dos poetas, realmente existia no outro (Robertson, 1777, I, 4, p.282).

Ao sugerir que a "imaginação dos poetas" não estaria tão distante assim da realidade, Robertson se volta contra Rousseau. Para compreender a razão dessa investida - aparentemente gratuita: o que faria um moralista nas páginas de uma história como esta? -, é preciso lembrar que o Discurso sobre a origem e os fundamentos da desigualdade entre os homens (1756) é, entre outras coisas, uma história conjectural do gênero humano. Na primeira parte da obra, a imaginação do autor se eleva por cima da experiência, e encontra o homem num estado de natureza que "não existe em parte alguma e provavelmente jamais existiu". Esse quadro imaginário fornece o padrão para medir os "progressos" do gênero humano e da sociedade tais como registrados na experiência histórica concreta. Convidandonos a "descartar todos os fatos, pois eles não tocam o que está em questão" (Rousseau, 1981, p.46), Rousseau instaura uma verdadeira "topologia da diferença" (na expressão de Bento Prado Jr. [2008, p.80]), pensando o homem civilizado como um acidente em relação ao homem natural, e não mais, como se costuma fazer na época, como o produto necessário de disposições naturais ou inatas (lembrando que para Hume essas duas expressões são sinônimos) (Hume, 1978, II, nota final; ed. facsímile). Rousseau reconhece que o estado de natureza "provavelmente jamais existiu e nunca existirá", mas afirma que sem "noções justas dele" não é possível "julgar corretamente nosso estado atual” (Rousseau, 1981, prefácio, p.40). Para chegar a tal noção, aparentemente contraditória, é preciso "não confundir o homem selvagem com os homens que temos diante dos olhos" (idem, parte I, p.51). Na passagem de Robertson que acabamos de citar, trata-se precisamente de recuperar os fatos, para mostrar que o quadro desenhado pela imaginação visionária de Rousseau não é tanto uma fantasia, como algo que a imaginação concebe em quase que estrita concordância com a experiência, que oferece, no continente americano, a fisionomia do homem natural de que tanto fala Rousseau. A História de Robertson é assim um exercício de adaptação, à análise das formas de organização política, do princípio que, segundo 
Foucault, orienta a história natural: a ordenação (e absorção) da diferença, num sistema de identidades (cf. Foucault, 1966, livro I, cap. 5).

Para dar força à sua demonstração, e, logo, à refutação indireta de Rousseau, o historiador escocês procede a um ajuste formal. Na História da América, a ordem dos eventos, e das razões que os explicam, não corresponde à da exposição. Ciente de que a inserção de uma história natural como preâmbulo à história civil da América não faria senão reproduzir a ordem adotada pelos grandes historiadores espanhóis, Robertson habilmente interpõe, à história civil, um hiato, uma digressão de história natural. Como explica o autor em outra parte,

ao apontar e explicar causas e eventos, não é necessário observar com acuidade cronológica a ordem do tempo; mais importante é manter em vista sua mútua conexão e dependência, e mostrar como a operação de um evento preparou o caminho para outro e aumentou sua influência (Robertson, 1762, p.125).

É lícito e mesmo necessário inverter a cronologia na exposição dos eventos, sempre que isso puder reforçar a "conexão e dependência mútua” entre eles na imaginação (Robertson, 1762, p.125), efeito produzido pelas transições entre as diferentes partes do discurso. Para que o homem natural desponte como questão de fato, é preciso que a imaginação do leitor tenha diante de si o quadro das circunstâncias em que esse evento se insere. Trata-se para Robertson, portanto, de adotar uma estratégia contrária à de Rousseau: se este convida a uma hipóstase da imaginação, interessa àquele promover sua coesão, isto é, permitir que ela se reconheça, como princípio de relações entre ideias, no quadro de uma experiência que, por suas dimensões, a ultrapassa (mas torna-se assim compreensível). ${ }^{4}$

A complexidade da tarefa transparece nas primeiras linhas da exposição "quando contemplamos o novo mundo, a primeira coisa que nos atinge é a sua imensa extensão" -, que advertem que estamos diante de um objeto imenso, que será posto em perspectiva (logo, em proporção) em páginas que têm tudo para ser inusitadas. Robertson mostra, através de uma ecfrase que é também uma espécie de cartografia discursiva, que o continente americano é impressionante sob todos os aspectos. A extensão das terras é pontuada por uma topografia de imponência: planaltos, planícies, pântanos, vales, se sucedem e alternam-se, culminando em cordilheiras. O clima é desconcertante: mais ameno nos trópicos, comparado a outras terras na mesma latitude, mais intenso nas extremidades. A natureza vegetal é tão vigorosa quanto acanhada é a dos animais (numerosas criaturas peçonhentas, poucos grandes mamíferos). As marcas da arte humana são raríssimas, e em proporção inversa ao vigor das forças naturais (Robertson, 1977, I, 4, pp.248ss).

Para se ajustar ao objeto, a prosa de Robertson se torna densa e caudalosa,

4É o princípio exposto por Hume nos Philosophical essays, III. 
as reconstituições geográficas e climáticas são impressionantes, as descrições da natureza (vegetal, animal ou humana) têm um vivo colorido, e as análises são abrangentes, versando sobre o lugar do homem na natureza e a origem da sociedade humana. Essas características de estilo, na verdade bastante raras, foram devidamente observadas por um arguto crítico do século XIX, o também escocês Dugald Stewart, que chama a atenção para o "efeito gráfico das narrações" que reconstituem o imenso espaço do continente americano e o preenchem com objetos que, por serem muito diferentes dos correspondentes na experiência dos europeus, têm tudo para incitar a curiosidade do leitor, despertar suas paixões e animar sua compreensão da obra. A narração gráfica, que desenha a cartografia do continente, é complementada por descrições não "pitorescas", mas sim calcadas na "expressividade da linguagem”, a serviço da evocação de objetos que o leitor nunca viu por si mesmo. ${ }^{5}$ Tudo isso nos limites de uma prosa controlada por uma imaginação que, "cálida e vigorosa" (warm and vigorous), dosa o seu "entusiasmo", destilando-o em "passagens mais próximas do romântico (romantic)" (Stewart, 1802, p.157).

Características de estilo valiosas para delinear o traçado do limiar entre natureza e cultura - ou, nas palavras de Buffon, para encontrar, "no limite da sociedade, o limite da natureza" (Buffon, 2008, pp.1193-94) -, objeto que parece se furtar, por sua obscuridade, a uma determinação conceitual precisa, e que, consequentemente, não se presta a ser fixado em palavras. Impondo-se à imaginação do leitor, o continente americano se torna, com sua imensa extensão, com sua natureza crua, com seus habitantes selvagens, o objeto de uma experiência verdadeiramente sublime (tanto no sentido retórico do grandioso ou elevado quanto no psicológico do disforme ou sem limites). Tendo esse cenário como pano de fundo, a conquista do continente americano pode agora ser apreciada como empreitada ousada de conformação de um material arredio, prodígio tornado possível pelo avanço das artes e ciências nas nações civilizadas da Europa moderna, que levaram à expansão marítima e ao engrandecimento ou ruína dos Estados que a promoveram. A imaginação do leitor, primeiro dilatada, depois é acomodada a uma medida justa ao discernimento dos fatos e à compreensão de uma experiência histórica extraordinária. Tais são as providências que esse engenhoso prosador houve por bem tomar, para se contrapor, com firmeza, à investida praticamente irresistível da retórica de Rousseau em sua peça sobre o homem natural e os selvagens.

Talvez resida aí a grande originalidade da História da América: que o estilo em que a obra é escrita seja indissociável não somente da natureza do objeto, como da finalidade filosófica que Robertson tem em vista: provar que o estado de natureza, ou o liame entre a história e a natureza, não requer, para ser concebido, uma projeção para fora da história; ao contrário, o que se exige, do filósofo da natureza humana,

5 Cf. Dugald Stewart, 1802, vol.1, pp.156-157; e Hargraves, 2002, esp. pp.264 ss. 
é que ele tenha a lucidez de reconhecer que o tempo histórico não é linear, não se projeta como uma seta que percorre um espaço e vai deixando para trás, em sua trajetória, as etapas precedentes. Mais complexo, ele é o tempo da articulação, no presente, das diferentes etapas do desenvolvimento possível da natureza humana.

A aliança entre as qualidades de Robertson como historiador, prosador, e filósofo não escapou a um dos críticos mais argutos de sua época, Edmund Burke, que foi também dos primeiros, e certamente conta entre os mais perspicazes leitores da História da América. Agradecendo a Robertson por lhe ter enviado, como presente, um exemplar do volume IV, Burke tece um elogio razoado que deve ter deixado o historiador escocês bastante satisfeito consigo mesmo:

Parece-me que poucos livros fizeram tanto no sentido de esclarecer pontos obscuros, corrigir erros e remover preconceitos. Tendes ainda a chave do segredo de reacender o interesse por objetos que já foram tratados muitas vezes e nos quais tudo o que poderia alimentar uma chama parece ter sido consumido. Posso garantir que li muitas partes de vossa história com uma preocupação e uma ansiedade tão vivas como as de um leitor sem conhecimento prévio dos eventos. Além disso, lançastes uma nova luz sobre o atual estado das províncias espanholas, e fornecestes materiais e sugestões para uma teoria racional do que se pode esperar delas no futuro. Mas a parte que li com o prazer mais intenso é a discussão sobre as maneiras e o caráter dos habitantes do Novo Mundo. Sempre pensei, em concordância convosco, que possuímos, em nosso tempo, vantagens consideráveis no que diz respeito ao conhecimento da natureza humana. Para traçá-la em cada um de seus estágios e períodos, não é mais preciso recorrer à história; relativamente jovem, ela é um instrutor inapto. Os egípcios disseram que os gregos eram "crianças, em matéria de antiguidade"; de nossa parte, poderíamos dizer o mesmo dos egípcios, e também de todas as nações que, ao traçar esse progresso, não foram além de seus próprios limites. Agora, porém, o grande mapa da humanidade se desenrola de uma só vez, e não há estado ou grau de barbárie ou modo de refinamento que não tenhamos, simultaneamente, diante de nós. A civilidade da Europa, e a da China, tão diferente da primeira; o barbarismo da Pérsia, e o da Abissínia; as maneiras erráticas da Tartária, e as da Arábia; o estado selvagem da América do Norte, e o da Nova Zelândia. Receio apenas que não tenhas feito justiça, em um ou dois pontos, ao caráter do selvagem americano. ${ }^{6}$

Esse elogio (quase) incondicional é tão mais valioso por vir da pena de um escritor que, na mesma época, esboçara, por conta própria, redigir uma história da colonização da América (cf. Burke, 2009). É como conhecedor do assunto que Burke louva os méritos de seu colega. Começa com um comentário de estilo. Robertson escreve de modo a "reacender" (rekindle) o interesse mesmo por objetos que o

6 Burke a Robertson, 09/07/1777; in: The correspondence of Edmund Burke, vol. III, ed. George Guttridge. Cambridge: University Press, 1961. A citação entre aspas se encontra, de acordo com os editores, em Platão, Timeu, 22. As palavras de Burke a respeito de Robertson não surpreendem, se lembrarmos a elogiosa resenha de Burke (publicada em 1759) sobre a História da Escócia, obra que Burke considera "de primeiríssima classe", realizada por um autor "judicioso" que sabe "estender ou abreviar o relato (story) de acordo com a importância e o interesse" dos episódios. Graças a esse método "admirável" e "belo", o "leitor não se fatiga jamais, e paga o preço mais baixo que se pode imaginar por um máximo de instrução". The annual register for the year 1759, pp.489-90. Eighteenth Century Collections Online. 
leitor já conhece; passa a uma observação sobre os poderes analíticos a que esse estilo serve; e culmina com o resultado da obra como um todo, que, ao estudar os povos nativos da América, complementa o que Burke chama de great map of mankind $^{7}$ - nada menos que um quadro ou painel sinóptico do desenvolvimento completo da sociedade humana em cada um dos estágios que levam da barbárie à civilização, e que correspondem ao desenvolvimento das aptidões naturais do espírito. Trata-se, em suma, de uma obra que realiza com êxito o estudo histórico (no duplo sentido acima notado) da mente ou natureza humana - que, como sugere Burke, se especificaria a partir de formas de sociabilidade relativamente simples e por toda parte similares entre si (a selvageria, a barbárie e o despotismo admitem pouca variação), até chegar a uma multiplicidade de formas, que, embora tenham o mesmo grau de complexidade, são diferem na organização e disposição de seus elementos constitutivos (Europa, China). ${ }^{8}$

Nessa trajetória, do mais simples ao mais complexo, realiza-se o programa de uma história especial, cujo objetivo, sublime em sentido retórico, é nada menos que "deter as asas do tempo em seu voo, rumo ao abismo da obliteração" (history arrests the wings of time in its flight to the gulph of oblivion). ${ }^{9} \mathrm{O}$ historiador realiza esse feito ao retratar, com os signos da linguagem, toda uma época, que assim é registrada para a posteridade. Mas não se trata, no século XVIII, de uma época qualquer; por ter acesso ao desenvolvimento integral da natureza humana, a História de Robertson conduz à superação da história como ciência. Conforme visto, Burke ressalta que “Para traçá-la em cada um de seus estágios e períodos, não é mais preciso recorrer à história; relativamente jovem, ela é um instrutor inapto". Essas palavras se referem a uma limitação crônica da história civil, que esbarra em trevas sempre que precisa remontar a um passado longínquo, quando os homens ainda não registravam suas transações por meio da palavra escrita. Restringida ao uso avançado da linguagem, a experiência política do gênero humano é bastante exígua; ou, como observa Hume, temos "menos de três mil anos de experiência". ${ }^{10}$ Para contornar essa restrição, é preciso recorrer, como faz Robertson, à perspectiva da história natural, que não é temporal, mas sim espacial. Ao introduzir, no presente, uma configuração social que, na ordem evolutiva das coisas, pertence ao passado, Robertson provoca uma

\footnotetext{
7 Para o símile do "grande mapa da humanidade", cf. Whiters, 2007, em especial o cap.06.

8 Essa observação se refere à teoria dos estágios do desenvolvimento humano, adotada em sua época por Ferguson, Smith e Millar: em sua marcha rumo à civilização comercial, o gênero humano teria partido do nomadismo, passado pelo pastoreio e a agricultura e chegado por fim à produção manufatureira e à troca do excedente. Burke transpõe esse esquema para formas de organização política que correspondem com mais ou menos exatidão, na experiência, a esses estágios. Cf. Pococok, 2001, II, 17. Pocock não menciona, porém, a origem dessa teoria, nos fisiocratas (Turgot).

9 "History arrests the wings of time in its flight to the gulph of oblivion". Burke a Michael Smith, s/d, - Burke, 1958.

10 "Da liberdade civil” - Hume, 1985, p.87.
} 
ilusão inversa àquela, evocada por Burke em seu tratado do sublime, que se obtém quando giramos uma tocha acesa e criamos, no ar, um círculo de fogo: a vertiginosa aceleração produz a ilusão de um quadro estático. Já na história, é o quadro estático que oferece a ilusão de um movimento que, contudo, não se desenrola de fato no tempo. A teoria dos estágios admite uma sincronia que é atestada pela experiência (cf. Burke, 1990).

Entende-se agora que o único reparo de Burke à obra de Robertson talvez seja decisivo: "não ter feito justiça a uma ou outra característica própria do selvagem americano", pela descrição do qual Robertson, em geral, se destaca positivamente, assim como ele faz em relação a outros povos mais próximos do ideal civilizado. Burke não esclarece quais seriam esses pontos. Mas podemos arriscar uma hipótese segura, fiando-nos por uma nota inserida nessa passagem da carta de Burke pelo organizador desse volume de sua correspondência. Como observa George Guttridge, a resenha da História da América que fora publicada no Annual register, jornal editado por Burke, embora fosse "altamente elogiosa", queixava-se de que Robertson "ignora a eloquência e a poesia dos americanos, qualidades que contam entre as mais notáveis da espécie humana no estado de natureza selvagem”. Essa censura, seja ela ou não da pena de Burke (não há como decidir), é perfeitamente coerente com o teor desta passagem da Investigação sobre o sublime e o belo:

Os mais poderosos efeitos da poesia e da música se exibiram e talvez ainda se exibam onde essas artes [da eloquência] só se encontram em estado muito baixo e imperfeito. 0 ouvinte rústico é afetado pelos princípios que operam nessas artes mesmo quando elas se encontram na condição mais rudimentar, pois não tem habilidade suficiente para discernir defeitos. Mas, à medida que as artes avançam rumo à perfeição, a ciência da crítica avança no mesmo passo, e o prazer dos juízes é frequentemente interrompido pelas faltas que se descobrem mesmo na composição mais consumada (“Dissertation on taste”, Burke, 1990, p.37).

A especial veemência das línguas selvagens se explica pela rusticidade, tanto na expressão quanto na recepção característica de seus usuários. 0 "avanço das artes rumo à perfeição" apara essas arestas e, ao mesmo tempo em que torna mais delicado o uso da linguagem, aumenta as ocasiões de desprazer, com a aquisição de uma atenção às menores asperezas, e diminui a intensidade dos sentimentos causados pelas palavras, agora que as línguas se tornaram menos persuasivas. Como observa Burke em outra parte da mesma Investigação,

línguas muito polidas, elogiadas por sua superior clareza e perspicuidade, geralmente são deficientes em força (strength). A língua francesa tem essa perfeição e esse defeito. Enquanto que as línguas orientais e em geral as línguas dos povos mais impolidos, têm grande força (force) e energia de expressão (Burke, 1990, V, 7, p.160),

o que parece "natural”, posto que tais povos "não têm senso crítico na distinção das 
coisas" e são mais predispostos a "admirá-las". A proximidade entre as línguas de povos civilizados, mas não-europeus, e as dos selvagens, sugere que tais civilizações estariam mais próximas da selvageria; o que lhes confere a vantagem, no uso de suas línguas, de uma expressividade que dispensa a arte. Isso não quer dizer que entre as línguas mais artísticas estejam separadas das mais rústicas, apenas que a distância entre diferentes sociedades é resultado de um processo em que são trabalhados os mesmos materiais que se encontram por toda parte. Apesar de tudo o que separa o europeu civilizado do selvagem americano, a disparidade é menor do que parece. ${ }^{11}$ Robertson não teria reconhecido essa identidade sem a qual a diferença que tanto lhe interessa não pode ser avaliada integralmente.

Se a insuficiência a que se refere Burke for mesmo essa, é indispensável mencioná-la, pois um exame mais objetivo da eloquência selvagem teria permitido a Robertson reforçar sua posição contra Rousseau. As línguas "orientais ou selvagens" de que fala Burke têm uma "maneira mais cálida e passional", o que as torna mais aptas a promover o "contágio das paixões" que ardem no peito de um homem (cf. Burke, 1990, v, 7, p.160). Esse fenômeno é mais comum quando os homens se encontram reunidos, seja para festejar ao redor de fogueiras, seja para deliberar em assembléias. No último capítulo do Ensaio sobre a origem das línguas, desenvolvendo um ponto que vinha ruminando desde a Carta a d'Alembert, Rousseau afirma que as línguas antigas eram calculadas para o uso em assembléias, eram línguas livres já em sua prosódia (cf. Rousseau, 1993). Seria a eloquência selvagem manifestação do "espírito livre" dessas nações? Em certa medida sim, diz Burke: o nativo americano é livre, como livres (e ferozes, e indisciplinados, e inconstantes) eram os bretões e os germânicos na época dos romanos (cf. Gibbon, 2014, pp.107-140). Por isso mesmo, a eloquência oratória antiga, tão elogiada por Rousseau, supostamente moldada às exigências da liberdade das repúblicas de então, além de ser uma arte excelente é também o resquício de um estado de natureza concreto, de desordem e violência, ao qual seria melhor dar o nome de selvageria, e que continua a ameaçar as sociedades civilizadas, sob a forma do tumulto, da sedição, da facção, e da guerra civil - tão comuns em governos republicanos. Se é verdade, como afirma Rousseau, que as línguas civilizadas são inaptas à oratória, é porque os homens que as falam se acostumaram a algum grau de servidão e aprenderam que a liberdade não é por si mesma um bem. Para tanto, foi preciso que encontrassem o justo valor das artes e ciências, que produzissem riquezas e posses, que tornam mais agradável e mais fácil a convivência entre os homens, mesmo sob uma "tirania". Podemos nos deleitar com o esplendor da eloquência antiga; mas é bom considerar o preço a ser pago pela

11 Analogamente, dirá Burke, "a comparação entre as línguas celta, de um lado, e grega e romana, de outro, mostra que os habitantes da sul da Europa, na Antiguidade, são da mesma raça que os do norte" (Burke, 2008, p.161). 
adoção de uma constituição republicana. A história da liberdade, adverte Burke, em uníssono com Robertson, é mais delicada do que às vezes gostaria a nossa robusta imaginação.

Até pela data de sua publicação, a História da América não deixa de ser uma fábula acerca das relações entre liberdade e autoridade. Falar do continente americano, em 1777, a partir de uma perspectiva britânica, é referir-se, ainda que obliquamente, à situação das colônias inglesas na costa leste da América do Norte, territórios da Coroa que se encontram em pleno estado de secessão. Provavelmente por isso, Robertson não escreve a história das treze colônias, cuja ausência, ao lado daquela da história das colônias portuguesas, faz da parte política da obra uma história da América espanhola. E o que é, aos olhos desse escocês, a conquista da América pelos espanhóis, senão a instauração de um princípio de constituição civil de liberdade regrada - ali onde tudo o que se encontrava era a liberdade selvagem? Por essa ótica, a secessão das colônias inglesas despontaria como mais um capítulo, em aberto, da tensão entre liberdade e autoridade, que marca a colonização do Novo Mundo pelos europeus (os colonos têm origem europeia, não são nativos).

Não será essa a última vez que a experiência histórica da época da Ilustração oferecerá a oportunidade de testar o esquema histórico delineado por Robertson. Onze anos após a publicação da História da América, eclode na França uma revolução que coloca a Burke um desafio muito claro: o da interpretação de um fenômeno histórico inesperado e singular à luz de um esquema geral que se pretende, nas páginas de Robertson, legitimado pela experiência.

A primeira coisa a notar é que a Revolução Francesa ameaça rasgar o grande mapa entrevisto por Burke a partir de Robertson. O que significaria, com efeito, em termos de legibilidade dessa cartografia da civilização, o retrocesso da grande monarquia europeia, símbolo da civilização comercial, a um estado de guerra civil equivalente, para todos os efeitos, a um regresso ao estado hobbesiano de natureza? $\mathrm{Na}$ metáfora de Burke, a cada continente correspondem, com certos ajustes, diferentes estágios do aprimoramento das artes e ciências (América e Oceania selvagens, Ásia bárbara, Europa e China civilizadas). O que fazer quando uma das ciências que é apanágio de homens civilizados - a filosofia - é e torna-se a aparente causa da ruína desse delicado sistema de semelhanças, proximidades e distâncias, ao tornar incerto o lugar da França, e, por decorrência dos Estados vizinhos?

$\mathrm{Na}$ primeira de suas inventivas contra a revolução, redigida ainda em 1790 e enviada a um interlocutor anônimo - provavelmente um simpatizante da causa revolucionária, Burke não hesita em atribuir à filosofia em geral - Montesquieu, 
Voltaire e Rousseau - a responsabilidade pelos desvarios que ele identifica na conduta da assembleia. ${ }^{12} \mathrm{Na}$ célebre carta de abril de 1791, elevada à condição de manifesto, é dos filósofos novamente que se trata; em dois registros. Ironicamente, quando Burke diz não ter dúvida de que entre as obrigações dos soldados franceses consta a leitura das páginas de "Voltaire, d’Alembert, Diderot e Helvétius" acerca da imortalidade da alma (o que mostra que ele não estava familiarizado com esses autores); ou bem a sério, quando os iluministas são colocados em contraste desfavorável com a época dourada dos romances de cavalaria:

Não perdemos ainda (não ao que me parece) a generosidade e a dignidade do modo de pensar do século XIV, e tampouco regredimos a selvagens. Não fomos convertidos por Rousseau; não somos discípulos de Voltaire; Helvétius nunca foi popular entre nós. Ateístas não são os nossos pregadores; não temos loucos por legisladores (Burke, 1993, p.86).

É de uma regressão ao estado selvagem, contraposto agora - quem poderia adivinhar (Robertson certamente não) - aos dias de glória do século XIV, que se trata, em última instância, na Revolução. Os agentes desse movimento retrógrado, informa a terceira e última missiva de Burke, publicada em francês em fins de 1791, são os deputados da assembleia nacional,

Que recomendam à sua juventude que estude os inovadores que mais ousaram em matéria de moralidade. Sabemos que os líderes da assembleia disputam entre si, acaloradamente, para saber quem mais se assemelha a Rousseau. Na verdade, todos eles são similares a ele. Apropriaram-se de seu sangue, de seu espírito, de suas maneiras. Estudam-no, folheiam seus escritos e meditam sobre eles..., que se tornaram o cânon e as escrituras santas; e a vida do autor se tornou modelo de toda perfeição (Burke, 2012, pp.43-44).

Apesar do tom um pouco histriônico dessa passagem - uma multidão de deputados que lentamente, pelo poder da leitura, se transformam em réplicas de um filósofo já morto -, Burke tem clareza de qual o problema de tomar Rousseau como modelo a ser seguido pelos líderes da nação. Resenhara, na década de 1760, a Lettre a D'Alembert e o Émile. Assim como outros críticos, ele parte de uma premissa forte: "No one of the present writers have a greater share of talents and learning than Rousseau”. Colocando-o numa posição excepcional e única, poderá censurá-lo por defeitos tão mais imperdoáveis por parecerem proporcionais à grandeza de seu gênio. “Uma tendência ao paradoxo, que conduz à ruína da instrução mais sólida, uma disposição biliosa levada à beira da misantropia, e uma virtude austera levada à uma ferocidade insociável", tais são entraves ao afloramento integral de seu gênio. Burke concorda com d'Alembert: a retórica de Rousseau substitui o "solid learning"; a razão

120 texto dessa carta se encontra traduzido em Daniel Lago Monteiro, "Anarquia e Conformação das Coisas: algumas observações sobre revolução, história e linguagem em Edmund Burke" (Monteiro, 2012). 
disso é o gosto pelo paradoxo (cf. Pimenta, 2012). Qualidades conspícuas, como o amor pela virtude e uma certa melancolia, têm, para Burke, algo de monstruoso, ao menos no contexto do Discurso sobre a desigualdade. Essa "sátira sobre a sociedade civilizada e a instrução" cai bem a uma fantasia engenhosa, mas torna-se nociva para a sociedade ao minar as bases das "noções de certo e errado" e preparar o caminho para o “ceticismo universal” em relação às instituições sociais (Burke, 1759, p.479). O que não impede Burke de encontrar na Carta a d'Alembert "de longe a peça mais engenhosa, espirituosa e filosófica já composta a respeito de espetáculos teatrais". Pois, embora Rousseau não tenha perdido o gosto pelo paradoxo, trata-se de uma obra que pode ser comparada a outras ("esse assunto já foi muitas vezes discutido") e cujas limitações podem ser apontadas em relação ao que outros autores disseram a respeito. Quando deixa de ser inteiramente original, Rousseau se torna menos extravagante, mais "sólido" ou "filosófico", menos perigoso, mais legível, instrutivo até (idem, p.480).

Três anos mais tarde, em 1763, Burke continua se admirando do gênio de Rousseau, que em seu "tratado sobre a educação" aborda um tema que é de antemão desinteressante, tradicionalmente saturado de "lugares-comuns" e de observações que Burke considera simplesmente "banais". Mas Rousseau reserva sempre uma surpresa: "estar a par das noções mais aceitas a respeito de um assunto qualquer é saber quais não são as opiniões de Rousseau." Na Carta a d'Alembert o assunto, embora não seja novo, é interessante; no Emílio, um assunto batido e desinteressante ganha cores de novidade apenas pelo enfoque escolhido: "em seu tratado sobre a desigualdade entre os homens ele mostra o seu homem em estado natural; ems eu Emílio, trata de educá-lo." Partindo de um ponto discutível, para não dizer fantástico, o autor redige uma obra "extraordinária" na qual se discerne o "impraticável e o quimérico", "o censurável e o perigoso", “o capricho e o paradoxo”, "nobreza e profundo conhecimento", “o mais sólido sentido", “instruções da mais útil natureza." A cena do Emílio é diferente, mas nada mudou em Rousseau, cuja "viva imaginação" é extraviada (borne away) pelos mais diferentes objetos e cujo "eswtilo exuberante pinta todas as coisas com grande minúcia, e, mesmo assim, como um espírito extraordinário." Qualidades raras, e difíceis de controlar: "ele nunca sabe onde parar" (essa censura costumava ser dirigida, no século XVIII, ao estilo exuberante das orações de Cícero) (Burke, 1762, pp.225-226).

Burke conclui assim que o inigualável estilo de Rousseau tende a um excesso que parece tão incontrolável quanto genial. A imaginação de Rousseau padece daquela mesma fraqueza do orador que não sabe o que fazer com a fertilidade de sua inventiva, que ela não tem força para sustentar as figuras que introduz em seu discurso. O efeito é fulgurante, como não poderia deixar de ser, e Rousseau ilumina, instiga, provoca, dá o que pensar; sua eloquência ou veemência põe a perder o 
sentido das coisas, mas não nos deixa esquecer de que há um sentido nelas, talvez mais complexo do que poderíamos pensar, sem essa experiência única que é a leitura alguns de seus escritos. Mesmo o Discurso sobre a desigualdade tem para Burke o valor de premissa, sem a qual o Emílio não poderia ter sido composto.

Todavia, o que em Rousseau é visto como defeito, é identificado por Burke na Investigação como qualidade. O poder da poesia, diz Burke, é independente da formação de imagens na mente do leitor, ou ao menos de imagens claras e coerentes. Os quadros pintados por Virgílio, se bem analisados, não formam um conjunto sólido de partes relacionadas entre si; "essa estranha composição adquirida a forma de um corpo grosseiro" parece-nos sublime porque corresponde às leis de associação de palavras e idéias na imaginação: “a conexão pictórica não é requerida, pois o que se forma não é uma pintura de fato, o que em absoluto diminui o efeuto ad descrição" (Burke, 1990, V, 5, p.156). O quadro de Rousseau não é de fato um quadro real, é a descrição de um estado que não se conheceu, que talvez não tenha existido e que forma um contraste marcante com a atual condição do homem, a ponto de este se tornar irreconhecível nas feições do selvagem. A descrição de Rousseau é retórica, por isso menos clara e exata, mais vaga e sugestiva: "seu objetivo é afetar mais por simpatia do que por imitação, exibir o efeito das coisas na mente do orador, não apresentar uma ideia clara das coias em si mesmas" (idem, p.157).

Burke condena-o por seus excessos retóricos, não por sua contenção, e dirige a Rousseau uma censura de cunho ciceroniano - "a escassez dificilmente poderia ser mais censurável do que tal abundância” (Burke, 1762, p.225). O efeito nocivo dessa abundância se fará sentir, anos mais tarde, quando esses prolixos tratados de filosofia forem erigidos em manuais de conduta moral e política. $E$, dentre as mais nocivas de suas mensagens, encontra-se aquela que recomenda o estudo das maneiras do selvagem, não com vistas à compreensão do processo de aprimoramento da natureza humana, mas sim à demonstração da ideia de que a natureza humana é mais descontínua do que parece, menos coerente do que gostariam os filósofos, mais complexa, enfim, do que poderiam suspeitar os historiadores. Burke, arguto, fez mais do que entrever quais seriam os frutos dessa "filosofia frívola" (philosophie de (a vanité). Entende-se agora que a História da América possui ainda uma virtude que poderíamos chamar de terapêutica: assegura o leitor perturbado pela retórica de Rousseau de que tudo vai bem, nos domínios da natureza humana, e a frágil imaginação nada tem a temer - a não ser, é claro, que a filosofia se imponha a ela, desvinculada da história. É desse mal que padecem os deputados franceses: uma especulação descolada da experiência. O século dos historiadores filosóficos está pronto para se tornar, com o advento dessa Revolução que é também intelectual, a era da Filosofia da História. 


\section{Referências}

Buarque de Holanda, S. (1974). “'Prefácio' a Maria Odila da Silva Dias”. In: O fardo do homem branco. São Paulo: Companhia Editora Nacional (Brasiliana).

Buffon, G-L. (2008). «Des époques de la nature». In: S. Schmitt (ed.). Oeuvres de Buffon. Gallimard/Pléiade.

Burke, E. (1759). “An account of the books for the year 1759”. In: Annual register for the year 1759. Eighteenth Century collections on line.

. (1762). "An account of the books for the year 1762". In: Annual register for the year 1762. Eighteenth Century collections on line.

(1958). The correspondence of Edmund Burke, vol. I. T. W. Copeland (ed.). Cambridge: Cambridge University Press.

. (1961). The correspondence of Edmund Burke, vol. III. George Guttridge (ed.). Cambridge: Cambridge University Press.

. (1990). Philosophical inquiry into the original of our ideas of the sublime and the beautiful. Adam Phillips (ed.). Oxford: Oxford University Press.

. (1993). Reflections on the revolution in France. L. G. Mitchell (ed.). Oxford: Oxford University Press.

(2008). An abridgement of English history. New York: Cosimo Classics.

Cambridge University Press.

. (2012). Lettre à un member de l'assemblée nationale sur la revolution française et Rousseau. Patrick Thierry (ed.). Paris: Mille et une Nuits.

Cícero. (2008). The republic and the laws. Translated by Niall Rudd. Oxford: Oxford University Press.

Foucault, M. (1966). Les mots et les choses. Une archéologie des sciences humaines. Paris: Gallimard.

Gibbon, E. (2014). Ensaios de história. Tradução de P. P. Pimenta. São Paulo: Iluminuras.

Hargraves, N. (2002). The progress of ambition. Character, narrative and philosophy in the works of William Robertson. Journal of the history of ideas, 63(2), pp.261282.

Hume, D. (1983). The history of England from the invasion of Julius Caesar to the Revolution. 6 vols. William B. Todd (ed.). Indianapolis: Liberty Fund.

. (1985). Essays, moral, political, and literary. E. F. Miller (ed.). Indianapolis: Liberty Fund.

(1978). Philosophical essays concerning human understanding, ed. facsímile. Hildesheim/Nova York: Olms Verlag.

Locke, J. (1978). An essay concerning human understanding. P. H. Nidditch (ed.). Oxford: Clarendon Press.

Monteiro, D. L. (2012). Anarquia e Conformação das Coisas: algumas observações 
sobre revolução, história e linguagem em Edmund Burke. Dois Pontos 8(1), pp.11-22.

Pimenta, P. P. (2012). “O filósofo no espelho. Hume, Rousseau e d'Alembert”. In: A imaginação crítica. Hume no Século das Luzes. Rio de Janeiro: Azougue.

Pococok, J. G. (2001). A. Barbarism and religion vol. 2. Narratives of civil government. Cambridge: Cambridge University Press.

Prado Jr., B. (2008). A retórica de Rousseau. São Paulo: CosacNaify.

Robertson, W. (1762). “A view of the progress of society”. In: The history of Charles $V$ (1762). Eighteenth Century Collections online.

online. . (1977). The history of America (1777). Eighteenth Century Collections

Rousseau, J. J. (1981). Discours sur l'origine et les fondements de l'inegalité parmi les hommes. Braunstein (ed.). Paris: Nathan.

Flammarion.

(1993). Essai sur l'origine des langues. Catherine Kintzler (ed.). Paris:

Stewart, D. (1802). Account of William Robertson. In: The works of William Robertson. $2^{\mathrm{a}}$ ed. Londres.

Whiters, C. J. (2007). Placing the Enlightenment: thinking geographically about the age of reason. Chicago: University of Chicago Press. 